\title{
Jealous Type Delusional Disorder
}

National Cancer Institute

\section{Source}

National Cancer Institute. Jealous Type Delusional Disorder. NCI Thesaurus. Code C94385.

A subtype of delusional disorder characterized by the central delusional theme that the individual's spouse or lover is unfaithful. 